\title{
Behind closed doors II: systematic analysis of prostate cancer patients' primary treatment consultations with radiation oncologists and predictors of satisfaction with communication
}

\author{
Thomas F. Hack 1,2*, J. Dean Ruether ${ }^{3,4}$, Tom Pickles ${ }^{5,6}$, Barry D. Bultz ${ }^{3,4}$, Dan Chateau ${ }^{7}$ and Lesley F. Degner \\ 'Faculty of Nursing, University of Manitoba, Winnipeg, MB, Canada \\ ${ }^{2}$ CancerCare Manitoba, Winnipeg, MB, Canada \\ ${ }^{3}$ Tom Baker Cancer Centre, Calgary, AB, Canada \\ ${ }^{4}$ Faculty of Medicine, University of Calgary, Calgary, AB, Canada \\ ${ }^{5}$ British Columbia Cancer Agency, Vancouver, BC, Canada \\ ${ }^{6}$ Faculty of Medicine, University of British Columbia, Vancouver, BC, Canada \\ ${ }^{7}$ Faculty of Medicine, University of Manitoba, Winnipeg, MB, Canada
}

*Correspondence to:

Room CR3018, Asper Clinical Research Institute/St. Boniface Research Centre, 369 Taché Avenue, Winnipeg, Manitoba, Canada $\mathrm{R} 2 \mathrm{H} 2 \mathrm{~A} 6$. E-mail: thack@sbrc.ca

Received: 14 October 2010

Revised: 22 March 2011

Accepted: 25 March 2011

\begin{abstract}
Objective: The purpose of this investigation was to explicate the content of primary treatment consultations in prostate oncology and examine the predictive relationships between patient, significant other, and oncologist consultation factors and patient satisfaction with communication.

Methods: The recorded consultations of 156 newly diagnosed prostate cancer patients from three Canadian cancer centers were examined using the Medical Interaction Process System (MIPS). The MIPS findings, independent observer ratings of patient, significant other, and oncologist affective behavior, and derived consultation ratios of patient centeredness, patient directedness, and psychosocial focus, were used to predict patient satisfaction with communication post-consultation and at 12 -weeks post-consultation.

Results: Biomedical content categories were predominant in the consultations, accounting for $86 \%$ of utterances, followed by administrative $(9 \%)$ and psychosocial $(5 \%)$ utterances. Postconsultation satisfaction with communication was significantly lower for patients whose significant others were rated as more assertive during the consultation, and those rated as more anxious during the consultation. Patients who were rated as more anxious during the consultation, those with lower satisfaction with communication immediately post-consultation and those with shorter consultations were significantly less satisfied with communication at 12-weeks post-consultation.

Conclusions: Adjuvant treatment consultations in prostate oncology are characterized by a high degree of information-giving by the physician, a predominance of biomedical discussion, and relatively minimal time addressing patients' psychosocial concerns. Patients may benefit from oncologists who address anxiety and emotional distress during the primary treatment consultation, allowing sufficient time to ensure that patients leave the consultation with their communication needs having been satisfied.

Copyright $(\mathbb{C} 2011$ John Wiley \& Sons, Ltd.
\end{abstract}

Keywords: cancer; oncology; consultation; communication; satisfaction

\section{Introduction}

Prostate cancer is the most common cancer in Canadian men with an estimated 24,600 new cases in 2010 , constituting approximately $27 \%$ of all new cancer cases in men [1]. Treatment decision making in early-stage prostate cancer is complicated by the fact that there are four standard approaches used in the clinical management of this disease - radical prostatectomy, external beam radiation therapy, brachytherapy, and active surveillance - that are considered for most patients to have comparable survival rates [2]. Any benefits associated with these treatments, however, may be at the expense of side effects which have the potential to impair quality of life, and which differ among these four treatment options [3-7].

The likelihood of experiencing a clinically significant level of emotional distress following a diagnosis of prostate cancer is approximately $30 \%$ [8]. The period of diagnosis and treatment planning can be emotionally and cognitively taxing for these patients given the expanding menu of treatment options available, and the wealth of patient education materials delivered by health professionals and accessible via the Internet. Men with prostate cancer 
consult a variety of information sources during the post-diagnostic, pre-treatment phase of their disease [9]. Although there is a broad range of information available to these men, evidence suggests that communicating adequate information to sufficiently inform treatment decision making is often a problem [10-12], leaving a significant proportion of men feeling uninformed despite having accessed multiple sources of information [13]. Amid the concern and confusion of the treatment planning phase is the primary treatment consultation - an important, essential consultation during which prostate cancer patients begin their relationship with their primary oncologist or urologist and have their treatment options explained. A recent study reported that patients who spent the most time discussing their treatment options with their physicians and broader social networks experienced less negative affect at 1 and 6 months post-treatment [14].

Patient-health professional communication research has been guided by communication measurement tools. Several of these tools have been developed to guide research studies examining some aspect of patient-oncologist communication during consultations. A meta-analysis [15] and review [16] of these measurement systems suggest five global categories of patient-physician communication: (i) information giving; (ii) question asking; (iii) partnership building; (iv) rapport building; and (v) emotional support. In addition to communication measurement systems, new conceptual frameworks have been developed to inform theoretical discussions of patient-professional communication $[17,18]$.

The most common patient-reported outcomes to be assessed in communication studies include understanding of information, satisfaction, and wellbeing [19], with patient satisfaction being the most widely used $[20,21]$. In one study, $37.8 \%$ of prostate cancer patients reported being less than satisfied with the quality of communication with their oncologists about their diagnosis and treatment side effects [13]. Patient satisfaction and well-being have been shown to be positively related to several communication aspects of the cancer consultation, including having patients' questions and concerns answered during the consultation [22,23], and physicians who score high on patient ratings of their caring behaviors and information giving [24]. Patient satisfaction following the initial cancer consultation is predicted by the affective quality of the oncologist's communication style as well as the communication style of the patient [25].

It is difficult to synthesize the findings from studies that have measured patient satisfaction with communication as the primary outcome given the diversity in the way patient satisfaction has been conceptualized, differences in sample characteristics across studies, and the plethora of patient satisfaction questionnaires in use. Patient satisfaction instruments are also known for ceiling effects [26].
Although many arguments have been put forward to explain these ceiling effects, patient satisfaction with communication remains an important variable that is significantly related to psychological morbidity of patients [27]. Satisfaction with information provided accounts for a significantly high proportion of the variance in quality of life in men with prostate cancer [28].

Although various communication measurement systems exist, most studies that have used these measurement tools have reported on an a priori subset of preselected consultation factors. To our knowledge a 'complete set' or comprehensive account of the primary treatment consultation in oncology has not been reported. A detailed explication of key consultations in oncology may prove invaluable for identifying essential consultation factors for examination in intervention studies designed to enhance the quality of patient-health professional communication in oncology. The current research team previously published a detailed explication of the primary adjuvant treatment consultation in breast oncology [29].

The primary purpose of the current study was to conduct a similarly complete, systematic explication of primary treatment consultations in prostate oncology; providing a 'behind closed doors' examination of a representative subset of these consultations with respect to the content and mode of all patient, significant other, and physician speech. The secondary purpose of this study was to determine whether consultation features are predictive of patient satisfaction with communication immediately post-consultation and at 12-weeks postconsultation. Given the growing empirical voice promoting the merits of shared decision making in oncology, we hypothesized that consultations characterized by patient-centeredness, a psychosocial focus, and patient-directedness would generate significantly higher levels of patient satisfaction with communication than consultations lacking these descriptive characteristics.

\section{Methods}

\section{Patient sample}

Eligible patients included men with prostate cancer who presented to a tertiary or community oncology clinic for their primary treatment consultation, and who previously participated in a study of the benefits of providing men with prostate cancer with an audio-recording of their primary treatment consultation [30]. All patients were older than 18 years of age and discerned to be free of any cognitive impairment or other limiting factor precluding their ability to provide informed consent. Patients were accrued from cancer treatment facilities in three Canadian cities, and data analyses were run on a final sample of 156 patients. These patients were 
recruited from the clinics of 15 radiation oncologists at the British Columbia Cancer Agency, Vancouver, Canada $(n=8)$, the Tom Baker Cancer Centre, Calgary, Canada $(n=5)$, and Cancer Care Manitoba, Winnipeg, Canada $(n=2)$.

\section{Study design and procedure}

The study protocol was approved by the review committees for ethics in human subjects research at each institution, and all patients and oncologists provided informed, written consent to participate.

Prior to the treatment consultation, the clinical research nurse obtained informed consent and administered a patient socio-demographic and illness profile. The clinical research nurse met with each patient after the consultation to administer the patient satisfaction with communication measure and furnish assigned patients with their consultation audiorecordings. A copy of the patient satisfaction measure was given to each patient in a sealed envelope with an instruction to keep the envelope sealed until contacted by the research nurse approximately 12 weeks later, at which time the nurse phoned the patient to record the answers to the questionnaire items as provided by the patient via telephone.

\section{Consultation audio-recording sample}

Stratified random sampling was used to select the audiotapes to be coded. The recordings were stratified on the basis of oncologist to ensure the oncologists had statistically equivalent representation in the set of coded recordings. To account for the possibility that the practice style of oncologists might change with repeated tapings of consultations, the audiotapes were organized chronologically by date of interview prior to random sampling using random number generating software. To obtain a representative sample of the available recordings at the goal rate of at least one-third, $176(50 \%)$ of the 351 available audiotapes were randomly selected to be coded. This accounted for reductions in the number of audiotapes excluded as a result of low inter-rater reliability scores $(n=11)$ or such poor audiotape sound quality as to preclude complete analysis $(n=9)$. After the representative sample of recordings had been generated, a secondary convenience sample of five of the remaining audiotapes was generated for use in calculating inter-rater reliability estimates during preliminary training. The 156 coded audiotapes in the final sample constituted $44.4 \%$ of the available recordings, well above the goal rate of one-third.

\section{Medical Interaction Process System}

The Medical Interaction Process System (MIPS) [31] is an objective, reliable, and valid instrument for analyzing oncology consultations. The MIPS was developed by combining categories adapted from the Roter Interaction Analysis System with those derived from detailed examination of audiotapes [32] and videotapes [33] of oncology consultations. The MIPS classifies patient-physician exchanges in terms of 'content' and 'mode' of exchange. The basic coding unit is an utterance, for example, 'You need to have a scan because your cancer may have progressed' consists of two utterances.

Each unit of utterance is assigned one 'content' code and one 'mode' of exchange, and may be initiated by either the patient or oncologist. 'Content' categories (see Table 1) reflect the topics being addressed in each utterance. 'Modes' (see Table 1) refer to the process or function of an utterance, for example, 'giving information' or 'asking questions'. A coding example follows:

(1) Oncologist 'Do you have pain in the area of your cancer?'

(2) Patient 'I'm worried my cancer is spreading.'

\begin{tabular}{lllll}
\hline Unit & Speaker & Content category & Mode of exchange & Cue or concern \\
(1) & oncologist & medical & $\begin{array}{l}\text { asks closed question } \\
\text { gives information }\end{array}$ & cue \\
\hline
\end{tabular}

In addition to coding the content and mode of each utterance, utterances were also coded for the presence of an oncologist or patient 'concern' or patient 'cue'. Patient concerns are utterances that pertain to a current cause of anxiety for the patient, for example, 'I'm frustrated about not being able to perform sexually'. Oncologist concerns give voice to a current issue that is troubling them as a clinician, for example, 'I'm worried about your frequent pain sensation'. Cues are indicators of a patient's underlying pre-occupation and state of mind. Whenever a patient cue is coded, the response of the oncologist to the cue is recorded as (i) appropriate response; (ii) inappropriate response; or (iii) nonresponse. In this study, we supplemented the coding of patient cues and concerns with a coding category called 'inappropriate behavior' to capture either an oncologist communication omission or mistake independent of a patient cue or concern.

In addition to the coding categories already described, the MIPS includes 'global affective' categories that are rater scored based on the entire consultation. For the present study, we modified these global, affective categories to enable measurement of additional variables of interest, including the responses of a third party - usually a significant other. A total of 13 categories were scored using 4- or 5-point scales, including three general interview ratings (patient centeredness (possible range 1-4), patient directedness (1-4), psychosocial focus $(1-4)$ ), four patient ratings (anxiety (1-4), assertiveness (1-4), involvement in treatment decision making (1-5), and satisfaction with communication), three significant other ratings (anxiety (1-4), 
Table I. Medical Interaction Process System content and mode categories

\begin{tabular}{|c|c|}
\hline \multicolumn{2}{|l|}{ Content categories } \\
\hline Intro & Introductory greetings \\
\hline Medical & $\begin{array}{l}\text { All medical details pertaining to the } \\
\text { present consultation }\end{array}$ \\
\hline Omedical & Other medical matters \\
\hline Tests & Past and future test results \\
\hline Tmt & Main cancer treatment \\
\hline S.effs & Side effects of main treatment \\
\hline Drugs & $\begin{array}{l}\text { Treatments and drugs prescribed to } \\
\text { prevent/alleviate side effects caused } \\
\text { by treatment }\end{array}$ \\
\hline Ps/med & $\begin{array}{l}\text { A statement, question, or concern } \\
\text { which could relate equally to } \\
\text { psychological feelings or physical } \\
\text { (medical) symptoms }\end{array}$ \\
\hline Psych & $\begin{array}{l}\text { Psychological (patient's feelings } \\
\text { and emotions) }\end{array}$ \\
\hline L.style & $\begin{array}{l}\text { Health and lifestyle issues such as diet, } \\
\text { drug habits, complementary } \\
\text { therapies, and leisure pursuits }\end{array}$ \\
\hline Soc/dem & Social/demographic characteristics \\
\hline Soc/con & $\begin{array}{l}\text { Social/personal conversation not } \\
\text { directly connected with the } \\
\text { consultation }\end{array}$ \\
\hline Ad/prac & Administrative practical details \\
\hline End & Goodbyes, closing statements \\
\hline Uncoded & $\begin{array}{l}\text { Utterances that lack the necessary } \\
\text { information to code them }\end{array}$ \\
\hline \multicolumn{2}{|l|}{ Mode categories } \\
\hline Asks questions: & Expresses: \\
\hline I. Open question ${ }^{\mathrm{a}}$ & I. Irritation ${ }^{\mathrm{b}}$ \\
\hline 2. Closed question & 2. Gratitude ${ }^{b}$ \\
\hline 3. Leading question ${ }^{a}$ & 3. Apology ${ }^{b}$ \\
\hline 4. Multiple question ${ }^{\mathrm{a}}$ & 4. Empathy/psychological support ${ }^{\text {ab }}$ \\
\hline 5. Focused open question ${ }^{a}$ & 5. Laughter ${ }^{\mathrm{b}}$ \\
\hline Checks: & 6. Positive response ${ }^{b}$ \\
\hline I. Information & 7. Negative response ${ }^{b}$ \\
\hline 2. Understanding & Agreement \\
\hline 3. Summarizes ${ }^{\mathrm{a}}$ & Registers information \\
\hline Gives: & Facilitates speech ${ }^{\mathrm{a}}$ \\
\hline I. Information (neutral) & Interrupts \\
\hline 2. Information (positive) ${ }^{b}$ & Asks for repetition \\
\hline 3. Information (negative) ${ }^{b}$ & Seeks information \\
\hline 4. Re-assurance $\mathrm{ab}^{\mathrm{b}}$ & Directs/advises \\
\hline 5. False/premature assurance ${ }^{a b}$ & Requests/preference $^{c}$ \\
\hline Orientation $^{\mathrm{a}}$ & Inappropriate behavior ${ }^{a}$ \\
\hline
\end{tabular}

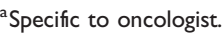

${ }^{\mathrm{b}}$ Affective categories.

${ }^{\mathrm{c} S}$ Ppecific to patient.

assertiveness (1-4), and involvement in treatment decision making (1-5)), and three oncologist ratings (friendliness (1-4), sensitivity (1-4), and quality of communication (1-5)).

The current research team elected to use the MIPS in the analyses of audiotapes given its relative advantages. First, the MIPS categories are sufficiently detailed to capture the diversity and complexity of information exchange. Second, the MIPS allows for the application of more than one code for a single mode utterance. Third, the nature of affective responses can be coded. Fourth, the MIPS allows for the coding of patient-oncologist nonsequential communication by allowing for the coding of patient signals for information, that is, cues, that may be addressed by the oncologist immediately, at any subsequent point during the consultation, or not at all.

\section{Medical Interaction Process System training and reliability}

The principal investigator and the two raters were trained by the developer of the MIPS, Dr. Sarah Ford, using the MIPS training manual. During the preliminary training period, inter-rater reliabilities were assessed on each of the five coded consultations, and training continued until the reliability estimate was above 0.80 for all content and mode categories, and above 0.95 for the total number of patient and oncologist utterances.

The randomized audiotapes were further stratified by data collection site and randomly allocated, using random number generating software, among the two raters. The two raters independently coded 81 and 75 , respectively, of the 156 consultations. Inter-rater reliability checks were performed after approximately every four or five coded consultations, by having the other coder code the same consultation to enable calculation of the percent agreement inter-rater reliability estimate. Any consultation having a reliability estimate of less than 0.80 (content or mode category) or 0.95 (total utterances) was removed from the final data set. There were 11 coded consultations that did not pass the inter-rater reliability check, leaving 156 consultations in the final set.

\section{Patient satisfaction with communication}

Patient satisfaction with communication was measured using the Patient Perception Scale [34]; a 9-item patient report measure of patient-centered communication with the oncologist during the consultation. This scale, reduced from the originally validated 14-item [35,36] and 12-item versions [37], includes items that assess the degree to which the patient feels the oncologist has adequately addressed the patient's disease concerns and been patientfocused during the consultation (e.g., How satisfied were you with the discussion of your problem? To what extent did the doctor listen to what you had to say? To what extent did the doctor explain treatment? How well do you think your doctor understood you today?) Each item is rated on a 4-point scale, and the possible range of scores is 9-36, with 9 representing highest possible patient satisfaction, that is, report of patient-centered communication. Cronbach's coefficient alpha for this measure in the present study was 0.88 .

\section{Data analyses}

UNIX SAS V 9.2 (SAS Institute Inc., Cary, North Carolina, USA) software was used for all analyses; descriptive statistics and correlation matrices were 
generated for all measures Almost all of the consultations consisted of three parts: (i) review of general medical history (e.g., previous illnesses, prior hospitalizations, family history of heart problems, etc.); (ii) physical examination; and (iii) discussion of the patient's cancer, that is, explanation of the disease and treatment. Given our primary interest in the latter and out of concern for patient privacy when listening to the recorded consultation alone or with others, any recording of the physicial examination (approx. 5 minutes) or general systems history (approx. 10 minutes) portion of the consultation was discouraged and omitted from analysis if present on the audiotape.

The presence of a third individual in the consultation, that is, a family member, spouse, partner or significant acquaintance of the patient, was noted in $111(71.2 \%)$ of the 156 consultations, for a total of 4,184 utterances representing $7.0 \%$ of all utterances. These utterances are presented in the results separately from those of patients. The presence of a resident or nurse was noted in a few consultations, representing $3.3 \%$ and $0.2 \%$ of all utterances, respectively. These other health professional utterances have been added to those of the oncologist in the presentation of findings.

Because of the multilevel structure of the data where patients were nested within physicians, independence of observations could not be assumed. Therefore, mixed models (aka multilevel regression analysis) were run to examine the relationships between consultation factors and the dependent measures (patient satisfaction with communication postconsultation and 12-weeks post consultation) using SAS PROC MIXED (SAS Institute Inc., Cary, North Carolina, USA). The predictor variables included patient age, education, and residence (urban/rural), the duration of the consultation in minutes, the presence of a significant other during the consultation, the 'global affective' rater categories for the patient, significant other, and consultation, and the three general consultation interview ratios (patient directedness, patient centeredness, and psychosocial focus) computed by formulas driven by content and mode combinations. These three ratios [29] were developed in consultation with Dr. Ford to capture groupings of content and mode combinations that reflect the current empirical literature on each of the three ratio topics. The following predictors were added to the model to predict patient satisfaction with communication at 12-weeks post-consultation: type of medical treatment received within the study period, whether or not the patient received a consultation recording, and patient satisfaction with communication post-consultation.

\section{Results}

\section{Explicating the consultation}

The demographic and treatment information for this sample is provided in Table 2. The average duration of the primary adjuvant treatment consultation (excluding the physical examination and historical review of general systems) was 19.4 minutes $(\mathrm{SD}=$ 9.3 minutes). The total number of utterances for the 156 consultations was 59,684 (Patient - 12,839 utterances $(21.5 \%)$; Significant Other $-4,184$ utterances (7.0\%); Oncologist - 42,661 utterances (71.5\%)). A breakdown of these consultations by content and mode is presented in Table 3, according to the percentage of utterances realized for each category. Biomedical content categories were predominant in the consultations, accounting for $85.5 \%$ of all utterances, followed by administrative (8.6\%) and psychosocial (5.9\%) utterances. It was most common for oncologists to lead the consultations and for the patients to follow along in the same content category; therefore, the percentages of content utterances per category are, not surprisingly, similar for oncologists, patients, and significant others.

With respect to mode categories, the most frequent oncologist mode was 'gives information' to the patient; an average of 205.4 utterances per consultation $(75.1 \%$ of the total utterances of the oncologist). The second and third most common modes for the oncologist were 'registers information' (13.0 utterances per consult; $4.8 \%$ of oncologist utterances), followed by 'directs/advises' (11.3 utterances per consult; $4.1 \%$ of oncologist utterances). The most common mode for patients was 'gives information' (31.6 utterances per consult; $38.4 \%$ of patient utterances), followed by 'registers information' (29.3 utterances per consult; $35.6 \%$ of

Table 2. Patient demographic and treatment information $(n=156)$

\begin{tabular}{|c|c|}
\hline Variable & No. of patients (\%) \\
\hline \multicolumn{2}{|l|}{ Age, years } \\
\hline \multicolumn{2}{|l|}{$($ Mean $=67.9 \mathrm{SD}=7.7)$} \\
\hline \multicolumn{2}{|l|}{ Education } \\
\hline$<=$ Grade 10 & $49(31.4)$ \\
\hline Grades $11-13$ & $4 \mid(26.3)$ \\
\hline >High school & $66(42.3)$ \\
\hline \multicolumn{2}{|l|}{ Residence } \\
\hline Urban & $109(69.9)$ \\
\hline Rural & $47(30.1)$ \\
\hline \multicolumn{2}{|l|}{$\begin{array}{l}\text { Prostate-specific antigen, } \mathrm{ng} / \mathrm{mL} \\
\quad(\text { Mean }=|1| . \mid \mathrm{SD}=10.9)\end{array}$} \\
\hline \multicolumn{2}{|l|}{$\begin{array}{l}\text { Gleason score } \\
\qquad(\text { Mean }=6.7 \mathrm{SD}=1.0)\end{array}$} \\
\hline \multicolumn{2}{|l|}{ Treatment - within study period } \\
\hline Hormone therapy only & 7| (45.5) \\
\hline Radiation therapy only & $16(10.3)$ \\
\hline Hormone + radiation therapy & $26(16.7)$ \\
\hline No treatment & $43(27.6)$ \\
\hline \multicolumn{2}{|l|}{ Consultation recording receipt } \\
\hline Yes & $105(67.3)$ \\
\hline No & $51(32.7)$ \\
\hline
\end{tabular}


Table 3. Primary adjuvant treatment consultation explicated by content and mode (\% of total utterances)

\begin{tabular}{lcccc}
\hline Content category & Patient & $\begin{array}{c}\text { Significant } \\
\text { other }\end{array}$ & Oncologist & Total \\
\hline Biomedical & $81.8 \%$ & $71.6 \%$ & $89.0 \%$ & $86.3 \%$ \\
Medical-cancer & 17.4 & 13.10 & 16.1 & 16.2 \\
Cancer treatment & 40.0 & 37.6 & 46.8 & 44.7 \\
Cancer side effects & 10.8 & 8.5 & 18.1 & 15.9 \\
Cancer tests & 3.3 & 4.3 & 3.0 & 3.1 \\
Cancer drugs & 0.8 & 0.9 & 1.2 & 1.1 \\
Medical noncancer & 8.5 & 6.5 & 3.1 & 4.5 \\
Psych/medical symptoms & 1.0 & 0.7 & 0.7 & 0.8 \\
Psychosocial & $8.9 \%$ & $12.0 \%$ & $3.5 \%$ & $5.2 \%$ \\
Psychological & 0.8 & 0.6 & 0.5 & 0.6 \\
Lifestyle/health & 2.8 & 1.6 & 1.1 & 1.5 \\
Socio-demographic & 1.6 & 1.7 & 0.6 & 0.8 \\
Social conversation & 3.0 & 4.7 & 1.3 & 1.9 \\
Personal conversation btw. & 0.7 & 3.4 & 0.0 & 0.4 \\
patient and sign. other & & & & \\
Administrative detail & $9.5 \%$ & $16.3 \%$ & $7.6 \%$ & $8.6 \%$ \\
Admin/practical & 8.5 & 14.8 & 6.9 & 7.8 \\
Intro/farewell & 1.0 & 1.5 & 0.7 & 0.8
\end{tabular}

\begin{tabular}{llll}
\hline Mode category Patient & $\begin{array}{c}\text { Significant } \\
\text { other }\end{array}$ & Oncologist Total \\
\hline
\end{tabular}

\begin{tabular}{|c|c|c|c|c|}
\hline \multicolumn{5}{|l|}{ Asks questions: } \\
\hline Open question & $\mathrm{n} / \mathrm{a} \%$ & $\mathrm{n} / \mathrm{a} \%$ & $0.3 \%$ & $2.2 \%$ \\
\hline Closed question & 5.7 & 10.0 & 1.9 & 3.3 \\
\hline Leading question & $\mathrm{n} / \mathrm{a}$ & $\mathrm{n} / \mathrm{a}$ & 0.3 & 0.2 \\
\hline Multiple question & $\mathrm{n} / \mathrm{a}$ & $\mathrm{n} / \mathrm{a}$ & 0.1 & 0.04 \\
\hline Focused open question & $\mathrm{n} / \mathrm{a}$ & $\mathrm{n} / \mathrm{a}$ & 0.8 & 0.5 \\
\hline \multicolumn{5}{|l|}{ Checks: } \\
\hline Information & 3.6 & 5.3 & 1.2 & 2.0 \\
\hline Understanding & 0.2 & 0.3 & 2.0 & 1.5 \\
\hline Summarizes & $\mathrm{n} / \mathrm{a}$ & $\mathrm{n} / \mathrm{a}$ & 0.8 & 0.5 \\
\hline \multicolumn{5}{|l|}{ Gives: } \\
\hline Information (neutral) & 38.4 & 38.8 & 75.1 & 64.7 \\
\hline Information (positive) & 0.01 & 0.0 & 0.4 & 0.3 \\
\hline Information (negative) & 0.01 & 0.02 & 0.5 & 0.3 \\
\hline Re-assurance & $\mathrm{n} / \mathrm{a}$ & 0.1 & 1.4 & 1.0 \\
\hline False/premature assurance & $\mathrm{n} / \mathrm{a}$ & $\mathrm{n} / \mathrm{a}$ & 0.03 & 0.02 \\
\hline Orientation & 0.3 & 0.2 & 3.0 & 2.2 \\
\hline Registers information & 35.7 & 27.9 & 4.8 & 13.0 \\
\hline \multicolumn{5}{|l|}{ Expresses: } \\
\hline Irritation & $0.0 \%$ & $0.0 \%$ & $0.01 \%$ & $0.0 \%$ \\
\hline Gratitude & 0.7 & 1.0 & 0.1 & 0.3 \\
\hline Apology & 0.1 & 0.2 & 0.1 & 0.1 \\
\hline $\begin{array}{l}\text { Empathy/ psychological } \\
\text { support }\end{array}$ & $\mathrm{n} / \mathrm{a}$ & 0.0 & 0.7 & 0.5 \\
\hline Laughter (positive) & 2.8 & 5.7 & 0.3 & 1.2 \\
\hline Laughter (negative) & 0.01 & 0.1 & 0.0 & 0.01 \\
\hline Positive response & 0.5 & 0.9 & 0.2 & 0.3 \\
\hline Negative response & 0.3 & 0.4 & 0.02 & 0.1 \\
\hline Asks for repetition & 0.04 & 0.1 & 0.1 & 0.1 \\
\hline Requests/preference & 0.03 & 0.1 & 0.0 & 0.0 \\
\hline Interrupts & 0.1 & 0.1 & 0.1 & 0.1 \\
\hline Agreement & 5.2 & 2.0 & 1.2 & 2.1 \\
\hline Facilitates speech & $\mathrm{n} / \mathrm{a}$ & $\mathrm{n} / \mathrm{a}$ & 0.1 & 0.1 \\
\hline Directs/advises & 2.0 & 0.8 & 4.2 & 3.4 \\
\hline Seeks information & 3.5 & 5.3 & 0.4 & 1.4 \\
\hline Inappropriate behavior & $\mathrm{n} / \mathrm{a}$ & $\mathrm{n} / \mathrm{a}$ & 0.2 & 0.1 \\
\hline
\end{tabular}

patient utterances). Similarly, the most common mode for significant others was 'gives information' (10.4 utterances per consult; $38.8 \%$ of significant other utterances), followed by 'registers information' (7.5 utterances per consult; $27.0 \%$ of significant other utterances). The average number of question utterances per consultation was 4.7 for patients, 2.7 for significant others, and 9.1 for oncologists (a question typically consists of 1-2 utterances, so the true number of questions asked by patients and oncologists is less than the mean utterance count). Of the 9.1 average question utterances of the oncologist, a little more than half of these utterances (5.2) represented closed questions (a question that requires a yes/no response). Open questions (questions that encourage patients to respond more fully) were rare among oncologists; an average of 0.8 utterances per consultation. The average number of utterances per consult for patients to check for information was 3.1 (1.5 for significant others), while oncologists checked for information or patient understanding an average of 8.7 utterances per consultation. Inappropriate responses by the oncologist were uncommon $(0.4$ utterances per consult), as were empathic responses by the oncologist (1.9 utterances per consult).

\section{Predictors of patient satisfaction}

The sample means and standard deviations for the patient satisfaction variables, global affective ratings, and MIPS consultation ratios are shown in Table 4 and the results of the regression analyses are shown in Table 5 (to maintain a reasonable table size, only statistically significant variables are presented in this table). Patient satisfaction with communication was high, both immediately post-consultation $(\mathrm{M}=11.4$, $\mathrm{SD}=2.9$; range $=9-24)$ and 12 weeks later $(\mathrm{M}=13.3$, $\mathrm{SD}=4.4$; range $=9-29$ ).

Patient satisfaction with communication measured just a few minutes after the primary adjuvant treatment consultation was significantly predicted by observer ratings of significant other assertiveness during the consultation, and a marginally significant

Table 4. Means and standard deviations for satisfaction with communication, global affective ratings, and Medical Interaction Process System consultation ratios

\begin{tabular}{lcc}
\hline Variable & Mean (SD) & Observed range \\
\hline Satisfaction with communication & & \\
Post-consultation & $11.4(2.9)$ & $9-24$ \\
I2-weeks post-consultation & $13.3(4.4)$ & $9-29$ \\
Global affective ratings & & \\
Patient & & \\
$\quad$ Anxiety & $2.18(0.43)$ & $\mathrm{I}-4$ \\
$\quad$ Assertiveness & $2.46(0.74)$ & $\mathrm{I}-4$ \\
Significant other & & \\
Anxiety & $2.07(0.53)$ & $\mathrm{I}-3$ \\
$\quad$ Assertiveness & $2.44(0.82)$ & $\mathrm{I}-4$ \\
Consultation & & \\
$\quad$ Patient directedness & $2.33(0.76)$ & $\mathrm{I}-4$ \\
Patient centeredness & $2.92(0.88)$ & $\mathrm{I}-4$ \\
$\quad$ Psychosocial focus & $1.98(0.79)$ & $\mathrm{I}-4$ \\
MIPS consultation ratios & & \\
Patient directedness & $0.48(0.18)$ & $0.04-0.86$ \\
Patient centeredness & $0.89(0.10)$ & $0.57-1.0$ \\
Psychosocial focus & $0.06(0.06)$ & $0.0-0.29$ \\
\hline
\end{tabular}


Table 5. Prostate sample statistically significant regression findings

\begin{tabular}{|c|c|c|c|c|}
\hline & $R$-square & $t$-value & d.f. & $p$-value \\
\hline $\begin{array}{l}\text { Post-consultation satisfaction } \\
\text { with communication }\end{array}$ & 0.116 & & & \\
\hline Patient anxiety (global rating) & & 1.93 & 1,38 & $0.062 *$ \\
\hline $\begin{array}{l}\text { Significant other assertiveness } \\
\text { (global rating) }\end{array}$ & & 8.54 & 1,38 & 0.006 \\
\hline $\begin{array}{l}\text { I2-week post-consultation satisfaction } \\
\text { with communication }\end{array}$ & 0.371 & & & \\
\hline Patient satisfaction post-consultation & & 43.34 & 1,39 & $<0.0001$ \\
\hline Patient anxiety (global rating) & & 7.84 & 1,39 & 0.008 \\
\hline Consultation duration & & 3.98 & 1,39 & $0.053 *$ \\
\hline
\end{tabular}

*marginal (trend) significance.

effect was seen for observer ratings of patient anxiety $(p=0.062)$ : patients whose significant others were more assertive and those who were more anxious reported the lowest levels of satisfaction.

The multilevel model for patient satisfaction with communication 12 weeks later required a two-step procedure. With the inclusion of patient postconsultation satisfaction with communication as a covariate in the analyses, not all variables could be included in the model simultaneously. An initial model was run with several of the nonsignificant variables from the model on post-consultation satisfaction with communication: age, sex, and residence. After establishing that these remained nonsignificant, a second model was run with the remaining variables. Satisfaction with communication at 12 weeks postconsultation was significantly predicted by patient anxiety, post-consultation satisfaction with communication, and marginally by consultation duration $(p=0.053)$ : patients who were rated as more anxious during the consultation, those with shorter consultations, and those with lower post-consultation satisfaction with communication were least satisfied. None of the consultation ratios of patient-directedness, patient-centeredness, and psychosocial focus were statistically significant predictors.

\section{Discussion}

The findings show that primary adjuvant treatment consultations in prostate oncology are characterized by a high degree of biomedical information giving by the oncologist. This is not surprising given the complexity of the disease trajectories and treatment regimens discussed during these consultations. More striking in these results is the relatively small amount of discussion time dedicated to psychosocial matters. The low ratio of psychosocial conversation to disease and treatment dialog is similar to that reported elsewhere $[29,32,38,39]$, as is the low percentage $(2 \%)$ of time that oncologists dedicated to checking patient understanding $[29,38,40]$. The determination of the optimal percentage or amount of oncologist's time to be dedicated to psychosocial matters is complicated by the fact that patient satisfaction with communication is influenced by both the quality and quantity of communication exchange: the fewest of choice words spoken to the patient at an opportune moment may result in greater satisfaction than a lengthy discourse lacking meaning for the patient. Furthermore, although studies have identified oncologist factors that are significantly related to patient satisfaction, the essential features of oncologist communication that are predictive of patient satisfaction with communication have yet to be conclusively determined.

Despite the infrequency of psychosocial discussion and low number of empathic utterances by the oncologists, the number of oncologist utterances deemed 'inappropriate' was also low, and the level of patient satisfaction with communication was generally high. It therefore appears that oncologists are general effective in communicating with patients; the significant predictors in this study are generally differentiating 'satisfied' patients from 'very satisfied' patients. This does not diminish the merit of the findings; evidence suggests that patients may report high satisfaction with consultations despite having unmet needs for information and emotional support following these consultations $[19,41]$. This apparent discrepancy between patient reports of unmet need and generally high satisfaction should be explored further. Doing so may enhance our understanding of the needs which are most strongly predictive of patient satisfaction with communication once fulfilled. This is especially important given that satisfaction measures, including the satisfaction with communication measure used in the present study, may suffer from ceiling effects. It is therefore possible that patients may have unmet needs that remain unrecognized, masked by high satisfaction scores. Furthermore, a possible limitation of the patient satisfaction measure used in the present study is that it may be too general in scope, lacking the kind of specificity necessary to capture the kinds of dissatisfaction that are tapped into by measures of unmet need.

The present findings show that satisfaction with communication immediately following the primary treatment consultation can be predicted by a global subjective assessment of the patient's level of anxiety and the significant other's degree of assertiveness during the consultation. The clinical implication of this finding is that health professionals may enhance patient satisfaction by providing information and addressing emotional distress to reduce patient uncertainty and anxiety. We hypothesize that the association between significant other assertiveness and patient satisfaction with communication may be explained, in part, by compensatory behavior on the part of the significant other (usually the prostate cancer patient's spouse): significant others may feel compelled to speak up on behalf of the patient during consultations when the patient feels uninformed or confused, or is reticent or too overwhelmed to speak. Although a significant other may represent the patient well during the consultation, the fact that this 
individual feels compelled to do so may indicate a patient who feels ill-equipped to ask questions during the consultation, and this feeling of discomfort may be expressed in a relatively low patient satisfaction score.

The importance of addressing patient anxiety during the initial treatment consultation and early in the disease trajectory is underscored by the finding that patient anxiety during the consultation was predictive of lower patient satisfaction with communication at 12-weeks post-consultation. Patient satisfaction with communication immediately following the consultation was positively associated with patient satisfaction with communication 12 weeks later, as was the duration of the consultation. Given that patients who had longer consultations were more highly satisfied at 12-weeks post-consultation, oncologists might enhance the satisfaction and well-being of patients by dedicating some consultation time to address areas of patient uncertainty and need that may be contributing to patient anxiety and dissatisfaction with communication. One should keep in mind, however, that the association between consultation duration and patient satisfaction is not well understood. Although it is possible that oncologists who have better communication skills spend more time with their patients during consultations, it is equally plausible that patients with more advanced or complicated disease, complex treatment regimens, or anticipated treatment side effects that are many and severe may have longer consultations because there is more information to be conveyed during the consultation regardless of the communication skill level of the oncologist. Research is needed to explore the reasons for lengthier consultations, and the impact of these factors on patient satisfaction with communication.

The present findings should be reviewed in the context of findings from studies of men with prostate cancer; however, most consultation analysis studies in oncology have been conducted with either women with breast cancer or both genders with mixed cancer diagnoses. Unlike the current study, a consultation analysis study of women with breast cancer [29] found that patients asked more questions than significant others, yet a study of question asking by a mixed group of oncology patients and their companions [42] found, consistent with the present results that companions asked significantly more questions than patients. The reader is cautioned that the present findings were obtained for consultations conducted by radiation oncologists and may not, therefore, be generalizable to urologists or urological oncologists.

Given the important role of partners of men with prostate cancer in exerting control over the management of illness information [43], the desire of most partners to be involved in the decision-making process, and the finding that partners may experience greater distress than patients themselves [44] and at levels above population norms [45], the role of the partner during communication exchanges between the oncologist and patient becomes important. Future studies in this area might benefit from examining the extent to which oncologists address, during key consultations, the dynamics of patient-partner communication, working with the couple as a distinct entity [46] to enhance the satisfaction and well-being of the patient and partner both as individuals and as a dyad. Oncologists may want to encourage effective communication between patients and partners, given that mutual, constructive communication between patients and their partners enhances marital satisfaction in the face of sexual dissatisfaction [47].

Recent findings of a randomized controlled trial showed that providing information, communication skills training, and personally designed prompts to newly diagnosed prostate cancer patients reduced illness and treatment uncertainty [48]. The authors concluded that the provision of disease and treatment information in the treatment decision making context should be preceded by patient training in communication skills prior to the treatment consultation. Future studies might assess the impact of pre-consultation communication skills training on patient-oncologist communication during the treatment consultation.

\section{Acknowledgements}

Supported by research grant \#016397 and research team grant \#010283 from the National Cancer Institute of Canada (NCIC) with funds from the Canadian Cancer Society (CCS) and the CCS/NCIC Sociobehavioural Cancer Research Network. Thomas F. Hack is supported by a Dorothy J. Lamont Scientist Award from the NCIC and the Canadian Institutes of Health Research (CIHR). Lesley F. Degner is supported by a Research Chair from the Canadian Health Services and Research Foundation and the CIHR.

\section{References}

1. Canadian Cancer Society's Steering Committee. Canadian Cancer Statistics 2010. Canadian Cancer Society: Toronto, 2010.

2. Jani AB, Hellman S. Early prostate cancer: clinical decisionmaking. Lancet 2003;361:1045-1053.

3. Pickles T, Ruether JD, Weir L, Carlson L, Jakulj F, and the SCRN Communication Team. Psychosocial barriers to active surveillance for the management of early prostate cancer and a strategy for increased acceptance. BJU Int 2007;100:544-551.

4. Letts C, Tamlyn K, Byers ES. Exploring the impact of prostate cancer on men's sexual well-being. J Psychosoc Oncol 2010;28:490-510.

5. Walker LM, Robinson JW. The unique needs of couples experiencing androgen deprivation therapy for prostate cancer. J Sex Marital Ther 2010;36:154-165.

6. Yu Ko WF, Degner LF, Hack TF, Schroeder G. Penile length shortening after radical prostatectomy: men's responses. Eur J Oncol Nurs 2010;14:160-165.

7. Christie KM, Meyerowitz BE, Giedzinska-Simons A, Gross M, Agus DB. Predictors of affect following treatment decision-making for prostate cancer: conversations, cognitive processing, and coping. Psycho-Oncol 2009;18:508-514.

8. Carlson LE, Angen M, Cullum J et al. High levels of untreated distress and fatigue in cancer patients. BrJ Cancer 2004;90:2297-2304.

9. Ramsey SD, Zeliadt SB, Arora NK et al. Access to information sources and treatment considerations among men with local stage prostate cancer. Urology 2009;74:509-515. 
10. McGregor S. What information patients with localized prostate cancer hear and understand. Patient Educ Couns 2003;49:273-278.

11. Sowden AJ, Forbes C, Entwistle V, Watt I. Informing, communicating and sharing decisions with people who have cancer. Qual Health Care 2001;10:193-196.

12. Wong F, Stewart DE, Dancey J et al. Men with prostate cancer: influence of psychological factors on informational needs and decision making. J Psychosom Res 2000;49:13-19.

13. Cegala DJ, Bahnson RR, Clinton SK, David P, Gong MC, Monk III JP et al. Information seeking and satisfaction with physician-patient communication among prostate cancer survivors. Health Comm 2008;23:62-69.

14. Beck AM, Robinson JW, Carlson LE. Sexual intimacy in heterosexual couples after prostate cancer treatment: what we know and what we still need to learn. Urol Oncol 2009;27:137-143.

15. Hall J, Roter DL, Katz NR. Meta-analysis correlates of provider behavior in medical encounters. Med Care 1998;26:657-675.

16. Stewart M, Brown JB, Weston WW, McWhinney IR., McWilliam CL, Freeman TR. Patient-Centered Medicine: Transforming the Clinical Method. Sage: Thousand Oaks, CA, 1995 .

17. Brown RF, Bylund CL. Communication skills training: describing a new conceptual model. Academic Med 2008;83:37-44.

18. Feldman-Stewart D, Brundage MD, Tishelman C, and the SCRN Communication Team. A conceptual framework for patient-professional communication: an application to the cancer context. Psycho-Oncol 2005;14:801-809.

19. Hack TF, Degner LF, Parker PA, and the SCRN Communication Team. The Communication goals and needs of cancer patients: A review. Psycho-Oncol 2005;14:831-845.

20. Ong LML, de Haes JCJM, Hoos AM, Lammes FB. Doctorpatient communication: a review of the literature. Soc Sci Med 1995;40:903-918.

21. Bredart A, Bouleuc C, Dolbeault S. Doctor-patient communication and satisfaction with care in oncology. Curr Opin Oncol 2005;17:351-354.

22. Butow PN, Dunn SM, Tattersall MH, Jones QJ. Computerbased interaction analysis of the cancer consultation. $\mathrm{Br} J$ Cancer 1995;71:1115-1121.

23. Uitterhoeve R, Bensing J, Dilven E, Donders R, deMulder P. Nurse-patient communication in cancer care: does responding to patient's cues predict patient satisfaction with communication. Psycho-Oncol 2009;18:1060-1068.

24. Roberts CS, Cox CE, Reintgen DS, Baile WF, Gibertini, M. Influence of physician communication on newly diagnosed breast patients' psychologic adjustment and decisionmaking. Cancer 1994;74(1 Suppl):336-341.

25. Ong LML, Visser MRM, Lammes FB, de Haes JCJM. Doctor-patient communication and cancer patients' quality of life and satisfaction. Patient Educ Couns 2000;41:145-156.

26. Urden LD. Patient satisfaction measurement: current issues and implications. Lippincotts Case Manag 2002;7:194-200.

27. Shilling V, Jenkins V, Fallowfield L. Factors affecting patient and clinician satisfaction with the clinical consultation: can communication skills training for clinicians improve satisfaction? Psycho-Oncol 2003;12:599-611.

28. Davies NJ, Kinman G, Thomas RJ, Bailey T. Information satisfaction in breast and prostate cancer patients: implications for quality of life. Psycho-Oncol 2008; 17:1048-1052.

29. Hack TF, Pickles T, Ruether JD, Weir L, Bultz BD, Degner LF. Behind closed doors: systematic analysis of breast cancer consultation communication and predictors of satisfaction with communication. Psycho-Oncol 2010;19:626- 636.

30. Hack TF, Pickles T, Bultz BD, Ruether JD, Degner LF. Impact of providing audiotapes of primary treatment consultations to men with prostate cancer: a multi-site, randomized, controlled trial. Psycho-Oncol 2007;16:543-552.

31. Ford S, Hall A, Ratcliffe D, Fallowfield L. The Medical Interaction Process System (MIPS): an instrument for analysing interviews of oncologists and patients with cancer. Soc Sci Med 2000;50:553-566.

32. Ford S, Fallowfield L, Lewis S. Doctor-patient interactions in oncology. Soc Sci Med 1996;42:1511-1519.

33. Fallowfield L, Lipkin M, Hall A. Teaching senior oncologists communication skills: results from phase 1 of a comprehensive longitudinal program in the United Kingdom. J Clin Oncol 1998;16:1961-1968.

34. Stewart M. Brown JB, Donner A, McWhinney I, Oates J, Weston WW. Impact of Patient-Centered Care on Patient Outcomes in Family Practice: Final Report. Thames Valley Family Practice Research Unit: London, Ontario, 1996.

35. Henbest R, Stewart M. Patient-centredness in the consultation. 2: does it really make a difference? FamPract 1990;7:28-33.

36. Stewart M, Belle Brown J, Donner A et al. The impact of patient-centered care on outcomes. J Fam Pract 2000;49:796-804.

37. Stewart M, Belle Brown J, Hammerton J et al. Improving communication between doctors and breast cancer patients. Ann Fam Med 2007;5:387-394.

38. Dimoska A, Butow PN, Dent E, Arnold B, Brown RF, Tattersall MHN. An examination of the initial cancer consultation of medical and radiation oncologists using the Cancode interaction analysis system. $B r J$ Cancer 2008;98:1508-1514.

39. Fagerlind, H, Lindblad AK, Bergstrom I et al. Patientphysician communication during oncology consultations. Psycho-Oncol 2008;17:975-985.

40. Gattelllari M, Butow PN, Tattersall MH. Informed consent: what did the doctor say? Lancet 1999;353:1713.

41. Brown RF, Hill C, Burant CJ, Siminoff LA. Satisfaction of early breast cancer patients with discussions during initial oncology consultations with a medical oncologist. PsychoOncol 2009;18:42-49.

42. Eggly S, Penner LA, Greene M, Harper FWK, Ruckdeschel JC, Albrecht TL. Information seeking during "bad news" oncology interactions: question asking by patients and their companions. Soc Sci Med 2006;63(11):2974-2985.

43. Nanton V, Osborne D, Dale J. Maintaining control over illness: a model of partner activity in prostate cancer. Eur J Cancer Care 2010;19:329-339.

44. Couper J, Bloch S, Love A, Macvean M, Duchesne GM, Kissane D. Psychosocial adjustment of female partners of men with prostate cancer: a review of the literature. PsychoOncol 2006;15:937-953.

45. Segrin C, Badger TA. Psychological distress in different social network members of breast and prostate cancer survivors. Res Nurs Health 2010;33:450-464.

46. Steginga SK, Turner E, Donovan J. The decision-related psychosocial concerns of men with localized prostate cancer: targets for intervention and research. World J Urol 2008;26;469-474.

47. Badr H, Taylor CL. Sexual dysfunction and spousal communication in couple coping with prostate cancer. Psycho-Oncol 2009;18:735-746.

48. Mishel MH, Germino BB, Lin L et al. Managing uncertainty about treatment decision making in early prostate cancer: a randomized clinical trial. Patient Educ Couns 2009;77:349-359. 